\title{
Earthquake-induced liquefaction in the coastal zone, Case of Martil city, Morocco
}

\author{
Mohamed El Hilali ${ }^{1, *}$, Youssef Timoulali ${ }^{1}$, Taj Benyounes ${ }^{1}$, Mohamed Ahniche ${ }^{2}$, Rabie El Bardai ${ }^{2}$, and Sahel Yattara ${ }^{3}$ \\ ${ }^{1}$ Earth Sciences Department, Scientific Institute, Mohammed V University in Rabat, Morocco \\ ${ }^{2}$ GeoTechMed Laboratory, Tetouan Park: lot ${ }^{\circ} 11$, Tetouan, Morocco \\ ${ }^{3}$ Abdelmalk Essaadi University, Geology Department, Faculty of Sciences, Tetouan, Morocco
}

\begin{abstract}
According to historical documents and Moroccan earthquakes catalogs, the coastal zone has suffered in the past from several earthquakes. Understanding how sedimentary basins respond to seismicwave energy generated by earthquake events is a significant concern for seismic-hazard estimation and risk analysis. The main goal of this study is to determine the distribution of the natural frequency value $(\mathrm{F})$, the amplification factor value (A), and the soil vulnerability index $(\mathrm{Kg})$ were carried out as an indicator for liquefaction potential sites in the Martil city based on the microtremor measurements. Liquefaction assessment was done at 96 stations using the HVSR approach provided by Nakamura (1989). According to the analysis results, the predominant frequency values range from about 0.31 to $5.63 \mathrm{~Hz}$, and the amplification factor values range from 3 to 15 . Based on these parameters, the vulnerability index $\mathrm{Kg}$ is determined, which can be used as a parameter in calculating the liquefaction potential of an area. This study shows supporting evidence for the first time that the HVSR of microtremors can be an excellent alternative indicator for an area's potential for liquefaction.
\end{abstract}

\section{Introduction}

Over the previous decades, many earthquakes have manifested worldwide, leaving behind it many injuries, deaths, and many buildings damaged. Experience shows that the catastrophic effects of earthquakes have continued for several years. Therefore, it is necessary to guarantee the safety of inhabitants through several correct programs designed to provide a secure living space.

Based on the geophysical and geological data (Fig. 1B), the plate boundary between Africa and Europe is well defined from west to east respectively from the Azores in the Atlantic to the west of the Strait of Gibraltar is punctuated by earthquakes of magnitude greater than 6 (Lisbon earthquake of 1755: $\mathrm{M}=8$. 7; 1941: $\mathrm{Ms}=8.2 ; 1969: \mathrm{Ms}=7.3 ; 1975: \mathrm{Ms}=6.7 ; 2007$ : $\mathrm{Mw}=6.1)$ tracing the activity of a transform fault. Beyond the Strait of Gibraltar, towards the east (the Alboran Sea and surrounding areas), the seismicity is low to medium and diffuse, characteristic of a continental collision zone [1].

Martil is a Mediterranean coastal plain located east of Tetouan city, specifically $10 \mathrm{~km}$ away, at the northwest edge of Morocco (Fig.1A). The results of the demographic projections of the prefecture M'diq Fnideq show that the population of the municipality of Martil would be 119128 inhabitants by 2030 against 63853 in 2014 (HCP 2014-2030), covering a surface of $87 \mathrm{~km}^{2}$.

\footnotetext{
Corresponding author: elhlalimohamed96@gmail.com
}
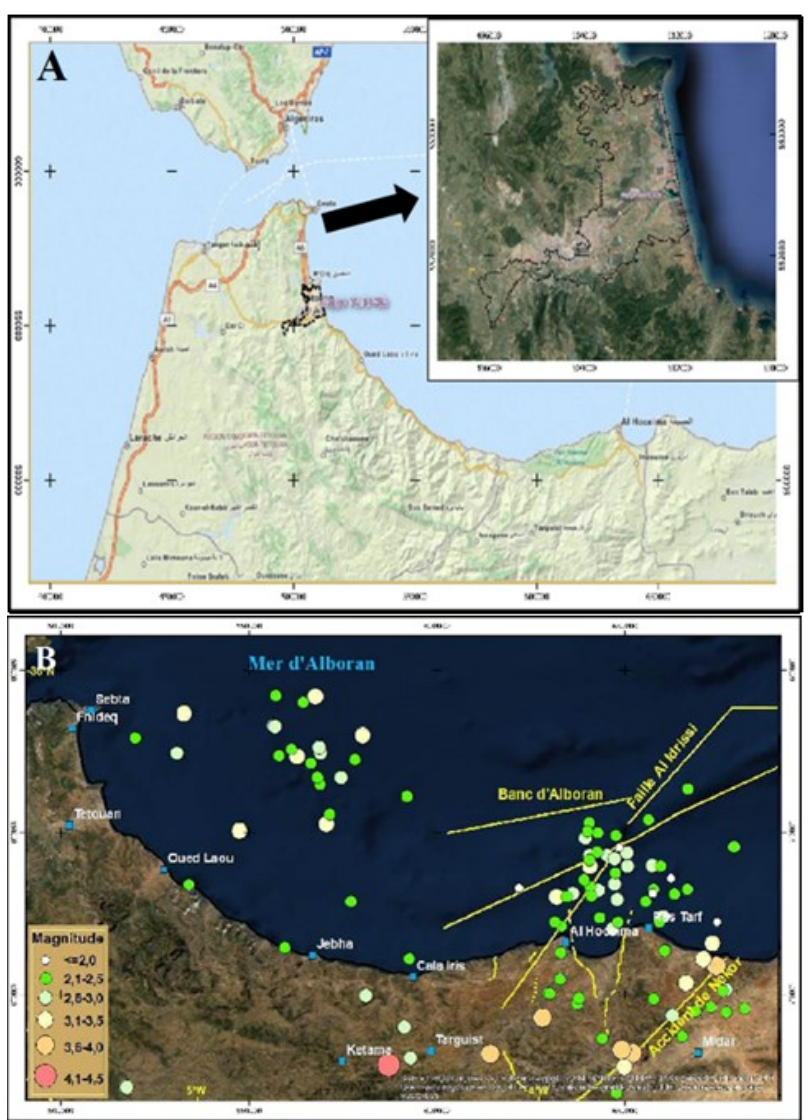

Fig. 1. The geographical location of Martil city with the seismicity of the Rif and the Alboran Sea (after Cherkaoui 2019). https://mtcherkaoui.wixsite.com/site 
According to these data, the population of Martil city has been increasing rapidly in the last decades and the future. For this reason, the present study is realized in this area to mitigate the seismic risk by assessing the soil liquefaction phenomenon as the main result caused by an earthquake.

Recently, the H/V technique [2] is becoming more popular with its data collection facilities due to it being easy to use anytime and anywhere. In this study, we analyzed the site response using the HVSR method in Martil city. Data were preprocessed using Grilla software 2014 (Fig. 2) to estimate the fundamental frequency (F), amplification (A), and the vulnerability index "Kg value" was calculated for each observation point as a means to determine the extent of liquefaction.

The present study mainly aims to show how the microtremor measurements can play a significant role in a liquefaction assessment [3] and show the possible impact of an earthquake in Martil city.

\section{Methodology}

The Microtremor method (MHVSR - Microtremor Horizontal to Vertical Spectral Ratio) is a technique that calculates the ratio of the horizontal to vertical Fourier (amplitude) spectra derived from microtremors recorded by a three-component sensor [4]. There is empirical evidence that the maximum or the peak in the MHVSR spectral ratio appears at the frequency, which equals the resonant frequency of sediments at a specific site [5]. Recently, to assess potential hazards associated with ground failure or liquefaction, the vulnerability index (or $\mathrm{Kg}$ value) derived from microtremor data may be evaluated. Among the various approaches to microtremor study, the $\mathrm{H} / \mathrm{V}$ spectral ratio technique introduced by Nakamura (1989) [2] was chosen for this investigation due to ease of application. This technique has been described in many papers.

By employing the $\mathrm{H} / \mathrm{V}$ ratio, we determined the predominant frequency (F) and the site's amplification factor (A). Nakamura also proposed the vulnerability index "Kg value" as a means to determine the extent of liquefaction [6].

For this purpose, he compared the results of the vulnerability index and the damage points in the Kobe earthquake and concluded that $\mathrm{Kg}$ is a suitable index for determining the vulnerable site points, such that each point with a higher $\mathrm{Kg}$ value is more damage potential. The $\mathrm{Kg}$ value is derived from the strain of ground structures. It can be defined as:

$$
\mathrm{Kg}=A^{2} / F
$$

With $\mathrm{A}$ is the amplification factor and $\mathrm{F}$ is the fundamental frequency.

After Nakamura, some scientists have used microtremor to liquefaction evaluation [7-8].

\section{Data collection and results}

This study used the microtremor measurements of 96 sites in Martil city during the period 2018 and 2019.

Microtremor measurements were taken at 96 points in Martil city. For all stations, the microtremors were measured, and the HVSR spectral ratios were calculated by the procedure used in the Grilla software packages prepared by the SESAME group.

Figure 2 shows the $\mathrm{H} / \mathrm{V}$ spectral ratio for some stations. According to the analysis, the fundamental frequency $(\mathrm{F})$ varies from 0.31 to $5.63 \mathrm{~Hz}$ within the study area. Also, the amplification factor (A) varies from 3 to 15 within the study area. Figure 3 shows the fundamental frequency and amplification factor in the study area. As shown in figure 3 for some recording stations, fundamental frequency and amplification factors have not been presented. Since the factories and highways have surrounded these stations in the city, accurate microtremor recording was impossible all day long [9], [10].

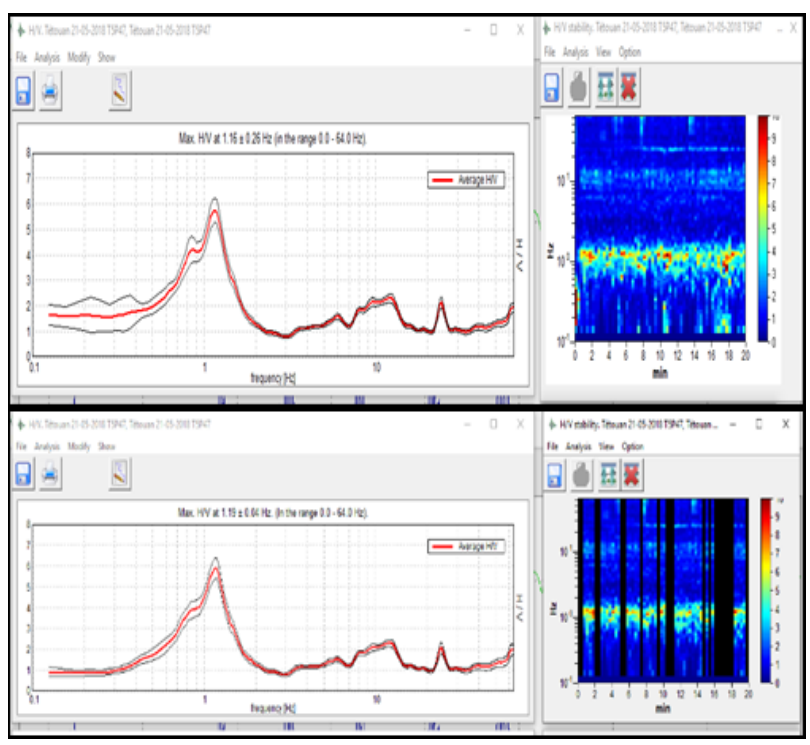

Fig. 2. $\mathrm{H} / \mathrm{V}$ spectral ratio

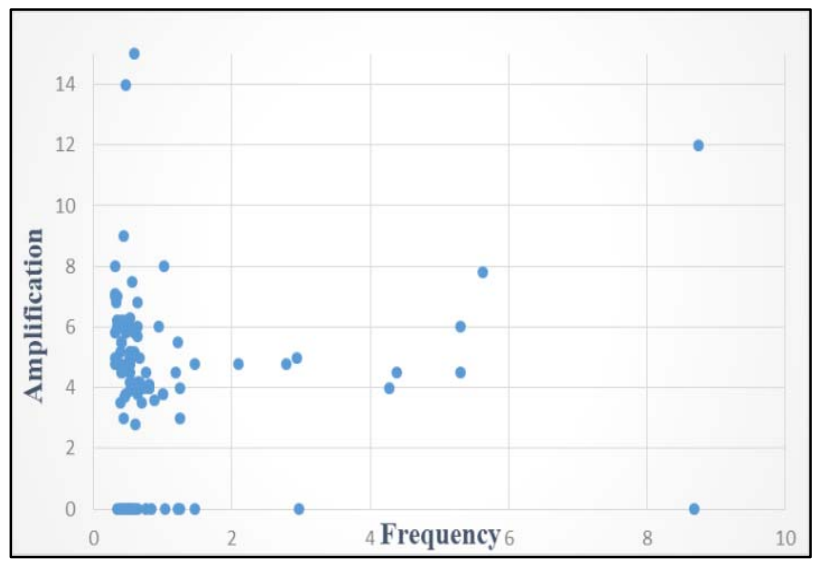

Fig. 3. representation of the fundamental frequencies with their amplitude in the different stations recorded in the city of Martil.

By using the results of figure 3, the $\mathrm{Kg}$ values are calculated for different stations. These results are 
indicated in figure 4. By reviewing the scientific literature, it has been concluded that the higher the $\mathrm{Kg}$ value, the more liquefaction potential will be. In fact, the $\mathrm{Kg}$ value has a qualitative meaning, for instance, the possibility of liquefaction occurrence.

As presented in figure 4, Martil City has a seismic vulnerability index going more than 30 . Several areas with a seismic vulnerability index of about 0-20 were found on some parts of the coastal area, especially at the north parts of Martil City. It is observed that in all the stations with $\mathrm{Kg}$ values higher than 30, liquefaction phenomena occurred. Consequently, the value of $\mathrm{Kg}=30$ can be considered a threshold value for these 96 stations, in that for all the stations of this region with a $\mathrm{Kg}$ value higher than 30, the occurrence of liquefaction phenomena is possible in stations with lesser values; this possibility does not exist.

For the areas susceptible to the phenomenon of soil liquefaction with $\mathrm{kg}>30$, as indicated in figure 4, having important amplitudes and a lithology essentially of ancient and recent alluvium typically of quaternary age resting on a substratum of Pliocene age. These alluviums are deposited by two rivers, which cross it transversally, the river Alila in the north of Martil and the river Martil that extends for $60 \mathrm{~km}$. However, other areas $(\mathrm{kg}<30)$ are less susceptible to this phenomenon than the previous one and have different lithologies of marly, sandy type, etc.

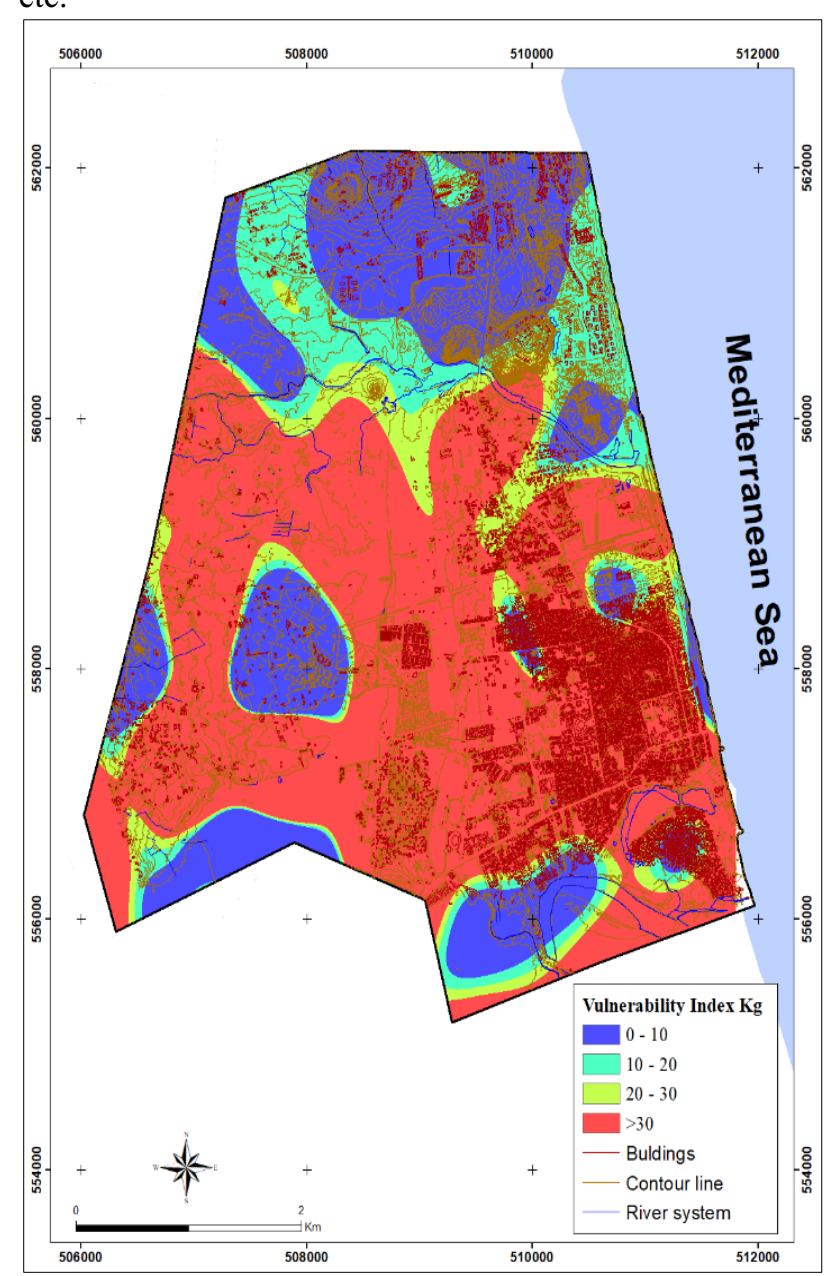

Fig. 4. Microzonation map of the vulnerability index $\mathrm{Kg}$

\section{Conclusion}

Due to the geological structure and the nature of the soils of the province of Tetouan and the prefecture of Fnideq-M'diq, site effects (local amplification phenomenon) may likely be observed in the case of seismic solicitation. It would be wise to carry out the necessary and adequate measures to evaluate such an effect and, consequently, anticipate any policy of mitigation of the seismic risk.

This paper presented seismic hazard mitigation based on the vulnerability index indicator for the Spatial Plan of Martil City, Morocco. The geophysical characteristics, such as amplification $(A)$, predominant frequency $(F)$, and seismic vulnerability index $\left(K_{g}\right)$, were presented. Generally, several areas in Martil City had larger amplification, especially in the places near the sea. It was indicated by the larger value of the fundamental frequency. The larger $\mathrm{Kg}$ values were found in the city center and the southern part of Martil City $(\mathrm{Kg}>30)$. It indicated that a significant seismic effect could occur in Martil City. Along this vulnerable area, the high density of people concentration existed. The finding obtained from this study could recommend the local government to consider the earthquake impact in Martil City, especially along in areas with a higher vulnerability index.

\section{References}

1. P. Tamponnier: Tectonic evolution of the alpine system in the mediterranean, punching and rigidplastic erading. bulletin of the geological society of France (1977) S7-XIX (3): 437-460 (1977).

2. Y. Nakamura, "A method for dynamic characteristics estimation of subsurface using microtremor on the ground surface". Quarterly Report of RTRI, Vol. 30, pp. 25-33 (1989)

3. HC. Huang, YS. Tseng "Characteristics of soil liquefaction using $\mathrm{H} / \mathrm{V}$ of microtremors in Yuan-Lin area, Taiwan", TAO, Vol. 13(3), pp. 325-338 (2002)

4. S. Molnar, J.F. Cassidy, S. Castellaro, C. Cornou, H. Crow, J.A. Hunter, S. Matsushima, F.J. Sanchez Sesma, and A. Yong : Application of microtremor horizontal-to-vertical spectral ratio (MHVSR) analysis for site characterization: State of the art. Surv. Geophys, 39, 613-631 (2018)

5. E. Field. and K. Jacob : The theoretical response of sedimentary layers to ambient seismic noise. Geophys. Res. Lett., 20, No. 24, 2925-2928 (1993)

6. Y. Nakamura "Real-time information systems for hazard mitigation", 10th World Conference in Earthquake Engineering, Spain, Madrid (1996)

7. S. Rezaei, AJ. Choobbasti, "Liquefaction assessment using microtremor measurement, conventional method and artificial neural network (Case study: Babol, Iran)", Frontiers of structural and civil 
engineering, DOI $10.1007 / \mathrm{s} 11709-014-0256-8$ (2014)

8. J. Saita, Y. Nakamura, T. Sato, "Liquefaction caused by the 2011 off the Pacific coast of Tohoku earthquake and the result of the prior microtremor measurement", 9th International Conference on urban earthquake engineering, Tokyo, Japan, (2012)

9. AJ. Choobbasti, S. Rezaei, F. Farrokhzad, "Evaluation of site response characteristics using microtremors", Gradevinar, 65, pp.731-741 (2013)

10. AJ. Choobbasti, S. Rezaei, F. Farrokhzad, Heidarzadeh P. Azar "Evaluation of site response characteristics using nonlinear method (Case study: Babol, Iran)", Frontiers of structural and civil engineering, DOI 10.1007/s11709-014-0231 (2014) 